\title{
Paced Ventricular Rhythm
}

National Cancer Institute

\section{Source}

National Cancer Institute. Paced Ventricular Rhythm. NCI Thesaurus. Code C92234.

An electrocardiog raphic finding in which the ventricular rhythm is controlled by an

electrical impulse from an artificial cardiac pacemaker. (CDISC) 